\title{
MANIFESTACIONES LITERARIAS MAPUCHES EN LA HISTORIA GENERAL DE EL REYNO DE CHILE Flandes Indiano, del R.P. Diego de Rosales.
}

\author{
Hugo Carrasco Muñoz \\ Universidad de la Frontera \\ Temuco.
}

\section{ANTECEDENTES.}

\begin{abstract}
En términos generales los cronistas o historiodores de los siglos XVI y XVII, y tombién misioneros y escritores, que fueron tan minuciosos y detallados para describir otro tipo de fenómenos que los impresionó en su "descubrimiento" del nuevo mundo, desconocieron, obviaron o reinterpretaron a su manera la existencia de una literatura aborigen. Esto es particularmente notorio en el caso de las manifestaciones literarias del pueblo mapuche o araucano, del cual apenas si fueron registrados textos en forma directa. Lo primero que se conoce son cuatro cantos de machi anotados en forma bilingüe por el P. Havestadt (1). También podría citarse un brevísimo texto presentado en medio de El cautiverio feliz (2), en transcripción fonémica del mapudungu $\bar{y}$ con una traducción libre del autor. Es otra de las escasísimas veces en que un autor se preocupa de presentar con fidelidad un texto indígena. En este caso Pineda y Bascuñán sitúa las condiciones de producción y transmisión del texto (una fiesta social en que participa la comunidad, ocasión propicia para la gestación de esta clase de discursos), identifica a su autor y sus propósitos (su amigo Quilalebo, que lo habría compuesto para él, manifestando el pesar que le causaba su ausencia), se refiere a la naturaleza del discurso (se trata de lo que él llama un "ramance" (3), del cual enfatiza su carácter métrico regular (4), y su índole de poena contado, y luego lo traduce libremente al español en una de las fomas métricas propias de la cultura de su época, en media lira. Por su interés y curiosidad, transcribimos ambos textos.
\end{abstract}




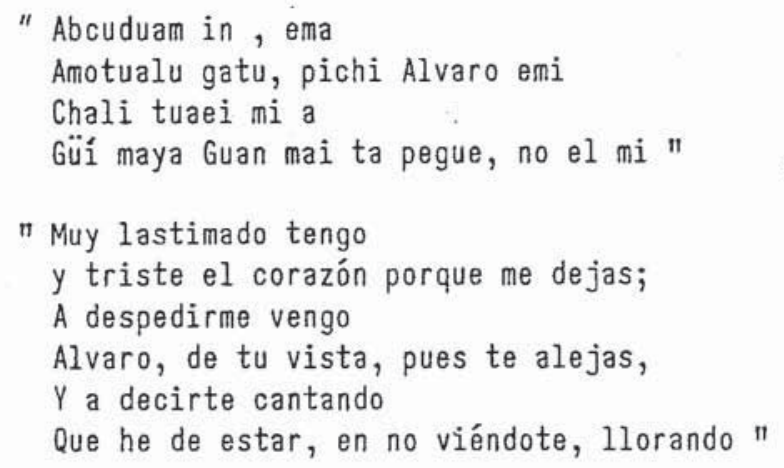

No obstante, como ya se ha señalado, los dos casos anteriores constituyen una excepción, ya que por lo general los escritores y cronistas no consideran este tipo de manifestaciones 0 , cuando lo hacen, es mediatizando el texto mapuche con su propio discurso narrativo o explicativo o, simplemente, refiriéndose a ellos mediante observaciones puntuales más o menos extensas y más 0 menos específicas según el caso.

Esta última es la actitud habitual entre los cronistas e historiadores de Chile al referirse a las manifestaciones literarios existentes entre los indígenas. Un ejemplo de esto lo constituye la Historia General del Reyno de Chile, del Padre Rosales (5). Sin embargo, este libro tiene el singular mérito de haber conservado y destacado uno de los mitos más importantes de la cultura mapuche, camo es el de Trentren y Kaikai, tanbién llamado. mito del Diluvio, y entregarlo en forma muy completa y detallada. Esta versión del mito se halla en el Cap. I del Libro Primero de la Historia General y, entre otras cosas, es de capital importancia por dar testimonio de la experiencia directa del autor con los mapuches de la época, por su afán de veracidad y precisión y por la antigüedad misma del texto: según Vicuña Mackenna, la Historia habría sido concebida hacia 1655 y el libro teminado en todos sus pomenores en dicienbre de 1674 (6).

En relación a este texto prehispánico presentado por el P. Rosales, nos interesa describir sus características fundamentales en el contexto de la Historia y ubicarlo, en un primer 
momento, en reloción a los géneros de la etnoliteratura mapuche. En un segundo momento, resulta de interés comparar el texto referido por el $P$. Rosales con alguna versión actual del mismo mito, para establecer los méritos de la versión que nos preocupa, que, por otra parte, es la más antigua $y$, al parecer, una de las más completas que se conoce.

Postulanos, como hipótesis de trabajo, que el mito de Trentren y Kaikai constituye uno de los "mitos de origen" de la cultura mapuche y que la versión del P. Rosales es de gran interés para su conocimiento por su antigüedad y amplitud, lo que tal vez se debe a que no manejó una versión única sino posiblemente varias que él refundió con gran acierto en la que insertó en su Historia.

Para demostrar lo anterior, primero desarrollaremos en forma crítica algunas nociones de literatura indígena que nos parecen de particular interés y pertinencia, deteniéndonos brevemente en los rasgos generales que caracterizan hoy a la etnoliteratura mapuche, desde un punto de vista más teórico-conceptual que descriptivo. A continuación se esbozan algunas características fundamentales de la organización discursiva de la Historia General, para situar allí el texto del mito que nos ocupa. En seguida, se intenta una descripción del texto, particulamente en el nivel secuencial del mismo $y$, por último, se realiza un somero análisis comparativo con varias versiones actuales del mito ciñéndonos al objetivo específico que nos hemos exigido.

\section{EL CONCEPTO DE LITERATURA ORAL INDIGENA.}

Entre los estudios que se han preocupado de la conceptualización de la literatura indígena en cuanto tal, es de particular interés un trabajo de Juan Adolfo Váżquez (7), porque se refiere específicamente al problema en relación a los indígenas latinoamericanos, entendiendo como tales "a los habitantes nativos de las Américas y sus descendientes siempre que conserven por lo menos algunas pautas y rasgos heredados o desarrollados desde la época precolombina" (1978:313). Vázquez define a la 
literatura carno "una colección de composiciones registradas consistentes en palabras significativas" (id.), lo que complementa agregando que, a su juicio, el hecho de que en la cultura occidental literatura sea sinónimo de letra se debe únicamente a que la moyor parte de las literaturas conocidas han sido conservadas en escritura alfabética. No obstante, parte de la literatura egipcia y china ha sido fijada sin el uso de letras, lo que todavía ocurre en China o Japón, y tanto en tribus de la selva o el desierto camo en sociedades civilizadas de países islámicos e hindúes existe aún gran cantidad de cantores y cuentistas iletrados. Por estas razones, habría que destacar que "el punto esencial es que las literaturas no consisten en escritos sino más bien en palabras. El arte de usar palabras en las composiciones orales precede al arte de escribir y no ha sido totalmente reemplazado" (1978:327, Nota 3).

Como puede observarse, el de Vázquez es un valioso intento por establecer un concepto amplio de literatura que abarque tanto sus manifestaciones escritas camo orales, incluso privilegiando estas últimas, lo que encuentra su fundamento en el hecho de que "las literaturas indígenas han sido siempre primariamente orales" (1978:325) y permite considerar como literatura los registros de versiones orales de toda clase de textos.

La limitación de este enfoque es que, por su misma amplitud, no describe con exactitud los rasgos definitorios del discurso literario, ni camo ente estético (lo que al parecer no le preocupa tampoco) ni en relación a otro tipo de discursos no literarios muy cercanos, como es el caso del discurso folclórico p.ej., sino que los incluye en un género próximo más amplio insuficientemente especificado.

Consecuente con esta noción de literatura manejada, el campo que Vázquez atribuye a las literaturas indígenas latinoamericanas es también muy amplio y abarcaría las siguientes áreas: prehispánica, colonial indígena tardía, indígena moderna, folklore indígena contemporáneo y literatura indigenista hispanoamericana contemporánea. Vale decir que, desde un punto de vista, incluye en la literatura indígena hispanoamericana tanto los 
textos elaborados por autores indígenas y entregados de manera directa, como los presentados por Cronistas y otra clase de escritores incluidos en sus propios textos con mayor o menor fidelidad; desde otro punto de vista, tanto la literatura en sentido estricto (de autores indígenas o hispanoamericanos modernos) como los textos verbales de carácter folklórico (8).

Dos trabajos de Iván Carrasco referidos en particular a la literatura mapuche, enfrentan previamente el problema general. En uno de ellos (9), propone explícitamente lo que se entendería por literatura indígena, aunque luego hace algunas salvedades: "el concepto de 'literatura' (a pesar de su origen etimológico) no incluye solamente a la expresión artística escrita de una comunidad humana sino también, con el mismo derecho, a la expresión oral, incluso cantada, en la medida que constituyen textos lingüísticos (excluyendo, lógicamente, todos los factores extratextuales, como tono de la voz, mímica, etc.); de igual modo se incluyen los textos que provienen de un creador determinado en el tiempo y el espacio, como los transmitidos por medio de una tradición, tanto los de carácter profano que acompañan al horbre en su quehacer cotidiano, como los que sirven funciones mágicas o religiosas en ciertos momentos de la actividad tribal" (1972:17).

Una de las salvedades se refiere a que no todo texto estructurado oralmente o por escrito es literario sólo por esto, (como sucede por ejemplo, con un texto histórico o cronístico, una narración de viaje o la historia de un malón), ya que clebe cumplir también otros requisitos (estructura de lenguaje mimético, creador de un universo "imaginario" coherente consigo mismo $y$ que, al mismo tiempo, es signo de la historia de un pueblo, en cuanto producto humano sujeto a las condicionantes socioculturales de la sociedad y la época, manifestante de la cosmovisión de un grupo humano determinado).

Otro aspecto que Iván Carrasco propone es la distinción entre obra literaria "indígena" (creada por hablantes indígenas en su propia lengua y desde su propia cosmovisión) y obra literaria "indigenista" (realizada por un escritor de raza y lengua no indígenas, desde una perspectiva ajena a la del pueblo que inten- 
ta novelar o poetizar, aun cuando intente asumir su conciencia, sus luchas o su historia).

A partir de estos criterios, distingue dos grandes sectores en la producción literaria mapuche, generalizable a otros pueblos indígenas: los que denomina literatura propiamente tal y folklore literario (1972:18-20).

En un trabajo posterior (10), busca precisar la condición discursiva de los textos mapuches en el orden de los hechos artísticos (1981:81), a partir de una actualización sistemática de las nociones empleadas. Concibiendo como literario un tipo de discurso escrito, carente de referente empírico, en el cual predomina la función poética o estética del lenguaje, lo que produce un sentido ambiguo, polisémico o plural del mismo (1981: 81-82) y entendiendo como texto literario el "producto de la actividad escritural de un individuo que organiza un texto único que tiende a singularizarse en el contexto de la tradición literaria y a permanecer inalterado en cuanto entidad lingüística, en la que todo se mira en función de un connotado estético, en otras palabras, habla (parole) fijada artísticamente" (1981:82), destaca la mera analogía formal de los textos literarios con los textos folklóricos, cuando de éstos se considera de manera aislada alguna o algunas versiones. La versión registrada de un texto folklórico sólo tiene en común con un texto literario su estructura lingúística, pero el texto literario único constituye su propio registro, no es más que lenguaje; en cambio, el folklore es el hecho mismo y se expresa por medio de diversos canales, uno de los cuales es el lenguaje.

En ningún caso puede confundirse un texto folklórico con el registro de una de sus versiones. "La obra folklórica es una unidad compleja, variable, constituida por un número indeterminado de versiones (textuales) que se producen en el momento en que un intérprete (en el sentido musical y no lingüístico del témino), integrante de la camunidad en que el texto aparece y se reproduce, lo actualiza mediante un acto de enunciación singular que intenta revitalizar las nomas que regulan ese complejo textual, al mismo tiempo que las modifica agregando, quitando 
y/o transformando algunas de ellas. Este acto, simultánecmente verbal y extraverbal, produce un nuevo texto, una nueva versión de la obra folklórica, condicionado no sólo por la tradición socioculturaly el contexto lingüístico de la comunidad (el conjunto de discursos análogos y sus respectivas versiones), sino también por la situación misma del acto enunciativo (la reacción del público, la hora y el tiempo de que dispone el intérprete durante el desarrollo del relato, su buena o mala memoria, su capacidad narrativa, su creatividad nomal, los sucesos imprevistos acaecidos en el momento mismo, etc.). Algunos de estos rasgos personales del intérprete quedan marcados en la enunciación o enunciado de los textos, otros sólo subsisten en la interpretación" (1981:82). El intérprete no es propiamente el creador individual de un texto folklórico, sino que lo es en conjunto con otros intérpretes del mismo texto en interacción con la camunidad. Por otra parte, su actividad no tiene camo fin fijar un nuevo texto, sino reproducir creativamente uno para llenar los objetivos prefijados por la comunidad en que se produce (entretener, educar, acompañar el trabajo, etc.), por lo que tiende más a ser idéntico 0 análogo a las versiones que él conoce y que la comunidad ha nomado como positivas para su modo de existencia, que a diferenciarse de ellas (cfr. 1981:83).

Lo anterior parece separar de manera absoluta los textos literarios y folklóricos, ya que difieren substancialmente en cuanto a sus respectivos modos de producción, de existencia, de conocimiento y de consumo. No obstante, "folklore y literatura se vinculan en un ámbito particular, el de los textos, ya que en el caso de la literatura el texto es su único modo de existencia, $y$ en el del folklore literario el texto es el factor que coordina y funcionaliza los diversos elementos extratextuales que lo acompañan para constituir el hecho folklórico" (1981:85). Por otra parte, es necesario distinguir entre textos artísticos y no-artísticos, para lo cual no basta con las clasificaciones usuales entre verso y prosa, fundadas en la forma lingüística, ni con los criterios de género, ni con la función de los textos en la sociedad. En términos generales, se puede denominar folklore literario (así como hay un folklore musical, coreográfico, religioso, ergológico, laboral, etc.), a un conjunto de textos 
que posea simultánecmente las propiedades del folklore y de la literatura (cfr. 1981:85).

Este es un problema sumamente corplejo que, por lo general, se elude o simplifica en extremo, evitando su formulación teórica o partiendo de ámbitos teóricos de gran amplitud en que se prefiere incluir estos tipos de discurso en otro mayor, lo que disfraza o encuadra el problema, pero no lo resuelve.

La experiencia de trabajo en terreno muestra que hay, en la actualidad, diferencia marcada entre la literatura artística escrita y el folklore, también llamado literatura oral, otorgándole variados sentidos a esta denaminación. Pero, por otra parte, es posible distinguir también, aunque con mayor dificultad, actitudes diversas tanto de los intérpretes (narradores, poetas, etc.) como de su auditorio, frente a textos al parecer de naturaleza también distinta. Estas actitudes diversas de la lengua oral y de la lengua escrita no es pertinente enfrentarla chora en toda su amplitud. Sólo es necesario reiterar que la distinción lengua escrita/lengua oral es útil para algunos propósitos, pero ha llevado también a gruesas simplificaciones. Si bien, por ejemplo, la literatura artística puede considerarse en la actualidad sobre todo un proceso escritural, no es menos cierto que otros tipos de escritura como cartas, diarios de vida, discursos científicos, etc., guardan diferencias de diverso grado con la escritura literaria. Por otra parte, tampoco puede sostenerse que las creaciones de la lengua oral, (no la lengua oral en sí, sino las manifestaciones discursivas orales), sólo por ser tales se agrupan indistintamente en un género común indiferenciado y pierden toda posibilidad de distinguir ciertos grupos o clases de textos que podrían ser considerados obras de arte.

En este sentido, es interesante también la postulación que ha hecho Fernando Lázaro sobre la existencia de un lenguaje literal, considerado desde la perspectiva de si un acto verbal comunicativo es destinado a perecer o busca perdurar en una $u$ otra forma (11). De este modo, habría que distinguir entre un lenguaje no-literal, destinado a perecer imediatamente después de producido el acto comunicativo, sea éste escrito $u$ oral (cfr. 
1980:154 y ss.) y un lenguaje literal, "empleado en comunicaciones que deben ser descifradas en sus propios téminos, y que así deben conservarse" (1980:160). Lo literatura, oral o escrita, puede considerarse como una de las munifestaciones (no la única) de este lenguaje literal. En otras palabras, la literatura sería una variedad específica, entre muchas otras, del lenguaje literal, en cuyos mensajes el emisor presta una especial atención a la técnica de cifrar (çfr. 1980:164 y ss.).

Esto implica una estructuración diferente a la de los mensajes no literales, ya que en el mensaje literal la estructura debe someterse a un "proyecto", que programa la "composición" dando especial importancia al "cierre" de la misma y a otros elementos estructurantes discursivos, vale decir, un repertorio de constricciones y de marcas formales que el emisor emplea en la organización del mensaje para asegurar la perdurabilidad del texto y que sirven al receptor para percibir la estructura y estructuración del mismo. Aunque esta teoría se halla todavía en elaboración, resulta muy fructífera para enfrentar algunos de los problemas anotados. Desde el momento en que el lenguaje literal es aquel que pemite la existencia de mensajes destinados a ser reproducidos en sus propios téminos, sean orales o escritos, es fácil descubrir mensajes (o más exactamente discursos) de ambos tipos que a la vez pueden caer o no en el ámbito de la literatura. Así, por ejemplo, una novela sería un discurso literal-escrito y una carta corriente un discurso no-literal también escrito (lo que puede formularse también al revés); un poema tradicional sería un discurso literal-oral y una explicación sobre cámo senbrar trigo un discurso no-literal tombién oral.

En un primer mamento, es dovio que esto confirma la necesidad ya señalada antes de distinguir entre discursos orales; que son parte de un "arte verbal", de otros que no lo son. Es decir, reafinma el punto de vista de autores camo Iván Carrasco que distinguen entre un folklore verbal li.terario, de otro folklore también verbal pero no-literario. Incluso el mismo Lázaro, en un párrafo de uno de sus trabajos, identifica literatura oral con folklore literario, usando explícitamente el término (12). No obstante, en su estado actual de desarrollo, la teoría tampoco 
ofrece explicación exhaustiva de la naturaleza específica del discurso literario, lo que, por lo demás, es un problema que en siglos no ha podido aún definirse con exactitud a pesar de los múltiples y variodísimos enfoques con que ha sido tratado.

Es evidente que hay problemas sin solución clara todavía. Por ejemplo, hay poemas o relatos orales de diversa índole, algunos de los cuales no cabe duda que pertenecen a la clase de discursos literales porque han permanecido (con las transformaciones propias de este tipo de textos) a trovés del tiempo en la memoria de los hablantes de la comunidad, pero también hay otros que pertenecen a la clase de discursos no-literales. La pregunta es: aparte de la voluntad (consciente o no consciente) perpetuadora del mensaje, que lleva al hablante a establecer cierto tipo de marcas formales reconocibles por los eventuales descodificadores del texto żqué otras condiciones deben cumplir estos textos para ser diferenciados de los otros camo literales? ìo las otras condiciones dependen del extratexto?, y si de éste żde, cuál de sus niveles?

El otro problema, tal vez mós delicado aún, es la distinción, entre los discursos literales orales, de discursos literales literarios y discursos literales no literarios. Hay algunos que, por ser mós semejantes a la literatura escrita, no ofrecen mayor problena: los poemas, por ejemplo. Pero, cierta clase de relatos que sólo existe en plenitud en su expresión oral, como los relotos míticos, ofrecen dificultades que distan mucho de estar resueltas: se trata más bien de mensajes literales, que se encaman en discursos que lingüísticamente manifiestan variaciones.

Conscientes de estas limitaciones, en forma provisoria $y$ sólo para efectos de este trabajo, consideraremos el relato mítico como una de las formas del folklore literario o literatura oral (no importa en este momento la denominación exacta), entendida camo una de las clases de discurso o mensaje literal existentes. En todo caso, nosotros preferimos la expresión etnoliteratura, por razones de índole teórica y metodológica, porque es más específica que "literatura indígena" y más omplia que "fol- 
Carrasco) MANIFESTACIONES LITERARIAS MAPUCHES...

klore literario", ya que incluye textos de valor folklórico y/o etnológico.

De manera más específica, consideraremos el mito camo una clase de relato oral perteneciente al ámbito de las tradiciones sagradas o primordiales de una comunidad; cuyo proceso de enunciación nos presenta a un narrador o destinador que asume la conciencia de la comunidad para relatar la experiencia de una historia que reactualiza un evento primordial hierofánico y fundador, considerado absolutamente veraz y digno de respeto, a un narratario o destinatario que comparte los sentimientos, ideas y creencias y que representa por lo general a una instancia de menor sabiduría y posterior en el tiempo. De este modo, median te el discurso, se establece la cadena que relociona al narratario con el pasado del cual el narrador extrae sus convicciones y su información, y a éste con el futuro en el cual se proyecta el narrador. Este cruce temporal, que muchos han querido ver como un círculo o una espiral ascendente, define la verdad permanente que establece la historia relatada o enunciado del discurso y que envuelve y trasciende a anbos interlocutores situándolos como "signos" representativos de dos momentos o instancias de la existencia de la comunidad (13). En el caso de un pueblo indígena, esto forma parte de su etnoliteratura, entendiendo ésta en el sentido ya especificado (14).

Entre los discursos mapuches, el mito (o, sí se prefiere, el relato mítico), se integra al ámbito del epeu (15). En efecto, el epeu es un relato, un discurso narrativo estructurado como tal y que puede referirse a cualquier contenido temático y no a uno solo en particular, camo había postulado la tradición crítica (16). De esta manera, el contenido del epeu es de una gran amplitud temática y abarca lo que habitualmente se ha denominado cuento de animales, como también el área de los relatos épicos, de los relatos picarescos y de los relatos míticos. El relato mítico ha sido a veces confundido con el nütram o nütrankan, por la noción de "verdad que implica para el hablante nativo y su auditorio culturalmente homólogo, rasgo que nosotros mismos destacamos al distinguir el "epeu-verdad" del "epeu-mentira" (cfr. 1981:27-28). No obstante, en téminos generales, el nütram 
- nütrankan es una conversación descriptiva o explicativa sobre algún tema, y no adopta necesariamente la estructura propiamente narrativa del epeu. Por eso, es relativamente común escuchar un epeu sobre, pongamos por caso, witranalve, que es acompañado o complementado por un nütram o explicación sobre el personaje mítico a quien se refiere la narración. Por lo general, el nütram se refiere a la experiencia personal del hablante en relación a la historia que narra. Caso típico es el de aquellos narradores que relatan en un epeu lo que ellos denominan "el cuento" o "la "historia", entendido como patrimonio de la comunidad y, en seguida, en un nütram o nütrankan, presentan su experiencia personal - sus juicios personales al respecto. Por otra parte, es fácil confundir epeu con nütram por el hecho de que casi necesariomente el epeu se relata en medio de una conversación sobre el tema, que a la vez precede y camplementa el relato. El epeu mítico abarca una temática bastante amplia, que incluye y a la vez manifiesta la mayor parte del pensaniento mítico mapuche.

\section{UN MITO MAPUCHE EN LA HISTORIA GENERAL}

La Historia General de el Reyno de Chile, Flandes Indiano, según revela su editor Benjamín Vicuña Mackema, fue iniciodo hacia 1655 y terminado en 1674, aunque fue publicado por primera vez en 1877-78. Es un extenso volumen ordenado en 10 Libros, en el aual el discurso central o discurso de la Historia General misma, se halla precedido por variados textos de diversa índole. En calidad de discursos del autor, los "Preliminares" dirigidos al 'Rey Carlos Segundo N.' retórica dedicatoria al monarca; con función de prólogo, una nota dirigida "Al lector"; y una breve "Protesta" final del autor. Como elementos accesorios requeridos por la nomativa de la época para la publicación del texto, la "Aprobación" correspondiente del Santo Oficio y del Tribunal de la Santa Cruzada, la censura del Ministro Provincial y la "Aprobación" del Provincial de la Orden y de otras autoridades eclesiásticas. Una tercera clase de discursos, son dos extensos poemas, en castellano $y$ en latín, que expresan el juicio de otros escritores sobre el autor y su obra y los recomiendan de manera encomiástica. A lo anterior, Vicuña Mackenna agregó una "advertencia del Editor", preámbulo a la Historia, una "Vida de 
Diego de Rosales" y un "Prefacio" que preceden el texto del P.Rosales y los documentos que lo ocrediton. Después del último libro de la Historia incluye una "Nota final" , y después del Indice por Capítulos un "Indice de las cosas más notables".

La organización en Libros del tratado está determinada por la diversidad de la materia propuesta camo objeto de discurso, propia de una historia "general". El discurso total se halla estructurado desde un criterio lógico y cronológico. El criterio cronológico rige la organización del discurso propiamente narrativo de sucesos históricos, dispuesto desde un criterio " $\infty$ ovo": prehistoria, descubrimiento de Gile (en el "libro I. Aborígenes de (hile. Dominación pervana") y distintos períodos de la conquista hasta teminar con la rebelión general posterior a las paces de Acuña. La lógica expositiva es irrefutable: primero se describen los orígenes del pueblo en estudio, luego se hace la descripción del territorio, y posteriomente se inicia la relación de distintos períodos cronológicos en forma graduada y sucesiva. Incluidos en este esquema general se hallan valiosos tratados sobre mitología, etnología, toponimia, botónica, zoología, ogricultura, artes militares, etc., lo que entrega una perspectiva global y completa del Reino de Chile en su prehistoria, geografía, historia y aultura. La presentoción de estos tratados incorpora a la narración otras unidades de discurso predominantemente explicativo y hoce concurrir variodas formas de discurso historiográfico, en especial las que en la época se identificabon como historia natural; historia moral, historia eclesióstica, historia militar, etc. Esto variedad temática y multiplicidad de modos narrativos corresponde justamente al carócter de "historia general" y otorga a la obra su "deleitable variedod", tan valorados entre los siglos XVI y XVII.

El Libro Primero de la Historia General; como se ha indicado antes, se refiere a los aborígenes de Chile; en paldoras del propio autor en él "se trata del origen de los indios chilenos, de su descubrimiento, costumbres, usos, ritos, süpersticiones, errores, ignórancios y policía en la paz: esfuerzo y valen-

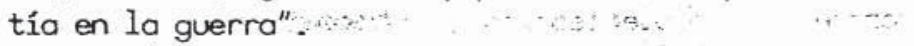


Vicuña Mockerna oprecia su validez y lo destaca entre los otros libros de la Historia. "El Libro I, que es ocaso el más interesante $i$ aquel cuya materia el autor conocía más a fondo (pues sabía la lengua araucana "como si fuese hijo de la tierra", "dice uno de sus críticos), está consagrodo a los doorígenes de Chile i a la época incarial o dominación pervana" (prefacio XLII). Incluso Vicuña Mackema mantiene este juicio a pesar de no conocer a fondo esta problemática y de reconocerse, implícitamente, no competente para opinar con propiedad al respecto. Esto es notorio auando empieza a analizar los grandes temas de la Historia, excluyendo en forma expresa este Libro I: "Analizaremos (...) con excepción del libro destinado a los doorígenes, que se presta a graves discusiones y divergencias, i cuyo interés es tal, según ya dijimos, que para formar de él un concepto justo sería menester reproducirlo entero" (prefacio XLIII).

Desde el punto de vista de su estructuración discursiva, el Libro Primero es similar al resto de los libros que confomon la Historia General.

No obstante, por la naturaleza misma de su contenido y por ser el texto inaugural de la serie, se generan en él fenómenos que conviene destocar.

En medio de su relato, el P.Rosales hace numerosas observociones sobre costumbres como las fiestas y el modo de celebrarlas 1:24 (Libro Primero, capítulo 24) y 1:25, la reloción de historias 1:1, Juegos 1:30, medicinas 1:30, modo de celebrar la paz 1:25, el arte de hablar 1:30, el arte de la magia enseñada por los hechiceros a los muchachos 1:30, función y cometido de los toqui, $1: 23$, vivienda $1: 26$, los poetas indígenas $1: 24$, etc. Junto a esto se refiere tanbién en ocosiones a determinadas creencias de orden mítico-religioso, cormo por ejemplo, los agüeros que encuentran en los sueños y en los pájoros 1:29, las almas corivertidas en moscordones 1:29, los pillones 1:29, los boquibuyes $\circ$ socerdotes 1:24, gigantes 1:18(17). Entre estas observaciones sobresalen con nitidez las referencias amplias y detallodas sobre el Diluvio, que se convierte en un auténtico 
relato inserto en el discurso mayor del Libro Primero, constituyente a su vez del macrodiscurso de la Historia. En estos casos, la situación discursiva varía, ya que el conocimiento del emisor sobre la materia narrativa también es relativa, como la del eventual destinatario, aunque en un grado desde luego menor. Este se debe a diversas causas: a) el conocimiento del emisor depende del discurso anterior de otros hablantes no precisados; b) presumiblemente estos hablantes han presentado diversas versiones, distintas y complementarias entre sí, que han sido recogidas por el hablante del segundo discurso o discurso de la Historia General, en un solo texto generalizante y uniformador; c) el discurso de estos hablantes 'in absentia' es asumido por el hablante del discurso histórico del P.Rosales como historia, en el sentido de que su contenido pasa a. ser reproducido, y como historia válida en el sentido de que al parecer es reproducida camo verdadera, aunque podría no coincidir con el conocimiento del mundo del enunciante reproductor; d) no obstante, esta actitud narrativa adopta en algunas oportunidades una variante: si bien el primer enunciado (o aspectos de él) es reproducido, reproduciendo por tanto el enunciado del discurso mapuche que lo fundamenta, el segundo emisor o hablante cristiano-español, va haciendo diversos camentarios que lo relativizan. Esto produce una especie de discurso mixto o estructuralmente híbrido en varios sentidos (18). .

Siguiendo uno de estos sentidos, se establece la relación con el otro fenómeno enunciado. El Libro Primero es el texto inaugural de una serie complementaria de textos que, a su vez, en cierta medida "fundan" también una realidad al recrear por medio de la palabra una historia que antes no existía como tal. El relato mítico mapuche va incluido en el Capítulo Primero de este libro, lo que desde un punto de vista formal constituye el lugar relevante de la serie, ya que es el comienzo o inauguración del primer texto de la misma. Sin embargo, hay aún más. El relato es uno de los mitos de origen del pueblo que se presenta a la Historia, por lo que también a nivel de contenido se trata de un texto inicial fundador. En otras palabras, estableciendo una correlación homológica, el relato mítico mapuche es el texto inaugural de la serie de textos que conformon la Historia General 
de el Reyno de Chile, tanto a nivel formal como de substancia del contenido.

Es altamente significativo y llama la atención que el P.Rosales, a pesar de todas sus reservas y comentarios derogatorios fundados en la creencia religiosa que sustenta, haga ingresar el mito en lugar tan privilegiado de su discurso. En la inauguración se sientan el fundamento, el origen y el lugar que ocupan dentro del ámbito de lo conocido (la Historia) hambre y pueblos que, por la reducción de testimonios materiales existentes, parecieran carecer de ese necesario fundamento. Frente a esta carencia, cobra realce el valor de la palabra camo fundadora de ese origen y manifiesto de las pruebas materiales inexistentes. A la vez, se muestra el intento de la conciencia hispano-cristiana del narrador por comprender una realidad y un modo de concebir el mundo y la existencia distintos al suyo, y conciliar su sistema de ideas y creencias religiosas con la orientación a la verdad externa u objetiva que sustenta como historiador y que le abre a establecer el mito indígena camo fundamento e incluso explicación de fenómenos (prueba de este... de aquí proceden...) o ilustración de "verdades" generales ("siempre la soberbia...").

Uha de las razones de lo anterior tal vez se halle en el capítulo XVIII del mismo Libro Primero. Refiriéndose a la valentía de los indios chilenos y a su condición de gigantes, rectifi$c a$ el segundo punto precisando que se trata de "grandeza de ánimo gigante" y que "la experiencia ha mostrado su extremada valentía, y que en hechos y valor exceden a los demás indios" (p. 109). Partiendo de este hecho probado por la experiencia, lo corrobora con la opinión de textos célebres, camo el de Fray Gregorio de León o Alonso de Ercilla. Al referirse a este último, se detiene en anotar que, aunque su historia se halle en verso, por esa sola razón no debe considerarse mentirosa o falsa, pues "la poesía no estorva a la verdad de la historia" sino ayuda a odomarla; "quando a lo historial, es muy puntual quanto dice de su valentía y esfuerzo, es muy sin encarecimiento, quitados hyperboles y encarecimientos propios de la poesía, que la sirven de adorno y sin ellos estubiera desaliñada" (p.109). Luego corroboro esta afimación aludiendo a autores clósicos, como Homero y 
Virgilio, y escritores sogrados como el Rey David, cuyas historias son más agradables "por la consonancia del verso, sin faltar a la verdad, pues si en las guerras y sucesos que cuenta se puede poner duda, ni se falta a la puntualidad de el suceso por las metáforas, hipérboles y adornos de la poesía. Así no se debe dejar de dar el crédito debido a tan famoso autor, poeta y historiador verídico por el adorno de su historia y por la dulzura con que la hizo sabrosa, ni por ser las cosas grandes y no vistas en otras naciones se deben calificar por mentirosas" (pp.109-110, el subrayado es nuestro). Como puede observarse, cuando el P.Rosales no tiene la experiencia directa de los hechos, confía en los textos escritos por gente que la posee. En este caso específico en que carece de textos escritos, cree en los textos orales existentes, bajo el supuesto de que aunque se refieran a 'cosas grandes y no vistas', no por eso van a ser necesariamente mentira. Es decir, cree, pero tampoco de manera absoluta. Por eso presenta, y luego comenta.

Lo que interesa determinar ahora es cómo se articula el texto del mito en el discurso de la Historia General. Esto ya está sugerido por la lógica expositiva de la misma. Situado en un país que se halla conociendo y frente a un pueblo extraño del que no se poseen antecedentes, el P. Rosales se interroga ante todo por el origen del mismo. Escudriñando, precisamente, el origen de los mapuches desde su doble perspectiva de historiador honrado y veraz, a la vez que hambre de fe y versado en la teología de su época, se plantea el problema a partir del diluvio universal referido en la Biblia y considerado en su tiempo camo históricamente existente. Sugiere al respecto que la primera dificultad se halla en averiguar por donde pasaron a las Indias Occidentales (como se llamaba al Nuevo Mundo), tantas naciones desconocidas, después del diluvio. Esta dificultad la halla particularmente remarcada en los Indios de Chile, tanto por su ubicación en el extremo del mundo conocido, camo por no hallarse entre ellos ningún documento material que lo explique (19). Aquí muestra con claridad su criterio de historiador (para explicarse una situación busca ante todo pruebas documentales: escritos, grabados, objetos materiales), los que no encuentra. Esto le llama la atención, ya que al comparar a los dborígenes chilenos 
con otros pueblos, éstos sí las poseen: jeroglíficos y pinturas estampadas, los mexicanos; quipos, cordones de lana de colores diversos, los peruanos. El problema es que, aunque él mismo reconoce lo diferente que son estos indios de otros, olvida en este caso que la cultura mapuche es de una clase diferente a otras culturas prehispánicas $y$, en particular, muy distinta a la de los aztecas e incas. En efecto, estos pueblos desarrollaron grandes civilizaciones materiales, que con justicia admiraron a los conquistadores. En cambio, el pueblo mapuche desarrolló una cultura verbalizada, que ha privilegiado desde siempre en alto grado la palabra humana, desdeñando o dejando en segundo plano otras manifestaciones culturales que a ellos no parece serles necesarias (como grandes vías de comunicación terrestre, templos - ciudades, por ejemplo, de las cuales prócticamente carecían a la llegada de los españoles).

En un segundo momento, al no encontrar pruebas que demuestren históricamente el origen del pueblo mapuche, el P.Rosales recurre a su preparación bíblica. Recuerda que incluso los documentos de incas y aztecas son incompletos, porque no alcanzon a llegar al tiempo de Noé y por esto su origen siempre es oscuro. Luego, postula que al carecer del conocimiento del verdadero Dios y la noticia verdadera de la creación del mundo y de los hombres, los pueblos indígenas "fingieron diferentes desvarios y fabulosos principios de su origen (...) y carmo no alcanzaron a saber como se multiplicaron los harbres después del diluvio, soñaron diferentes desvarios y creyeron en sus sueños: que donde falta la luz de la fe, todo es desvario y tropezar entre confusas sombras"... (Libro Primero:2) (20). Al respecto, señala el ejemplo de los incas, que se creyeron hijos del sol, o de otros pueblos que reconocen su origen en fuentes, logunas, cuevas y peñas. No obstante, se apresura en señalar que por tales errores los indios de América no deben ser considerados tan rústicos ni bárbaros (sólo debe lamentarse su ignorancia y el estar carentes de la verdadera luz de la fe), ya que griegos y ramanos hicieron lo mismo. Iricluso habría que agregar -piensa el Padre- que los indios americanos hacen esto sólo por desconocimiento de las Sagradas Escrituras y de la verdadera luz del Espíritu Santo (cfr.Libro Primero:3). 
Los indios de Chile carecen, por tanto, de toda clase de texto escrito (sagrado o profano) referido a la creación del mundo y del hambre, pero sí pueden encontrarse señales concretas de que el Diluvio existió y, por él, llegar a colegir la creación divina del universo y el ser humano (21). Estas señales (o signos) consisten en huesos de "ballena", conchas de mar y mariscos petrificados que se encuentran en lo más alto de la cordillera y que el diligente misionero y horbre de ciencia conoció en forma directa. Para él, el hecho de encontrar estos objetos en un lugar tan desusado probaría que en un tiempo anterior el Diluvio hizo subir los mares hasta anegar las cordilleras (22). De todos modos, aunque los indios chilenos pueden reconocer la existencia de un Diluvio general, el demonio se lo mezcla con múltiples errores, de tal modo que desconocen que la inundación fue para castigo de los pecados y "no se.persuaden a eso, sino a un diluvio de mentiras, que el demonio les ha enseñado $y$ persuadido, cuya tradición ha pasado de Padre a Hijos" (Libro Primero:4).

Esta observación es de extraordinaria importancia, puesto que señala en forma explícita que la historia del diluvio a que se refiere el P.Rosales consiste en una tradición oral, que es la forma nomal de transmisión de la literatura indígena de origen prehispánico, o etnoliteratura para nosotros.

A continuación, el P.Rosales presenta el relato del Diluvio, que es como él lo denomina, y que entre los mapuches corresponde a la historia de Trentren y Kaikai, entremezclado con observaciones y comentarios que hace al respecto.

Para mayor claridad, hernos reducido el relato a proposiciones S-P, anotando en la colurna de la derecha las observaciones del recolector. Las notas entre paréntesis son observaciones nuestras.

Texto de la tradición

Antiguamente, salió el mar y anegó la tierra.

\section{Comentarios}

No se sabe cuándo, porque no tienen medidas de tiempo. 
Algunos indios twyeron y se re fugiaron en las cimos de unós cerros altos llamados Tenten.

los cerros eran sogrados y allí se salvaron quienes subieron a ellos.

lantes que sucediera el dilubio - salida de mar, los indios fue ron avisados por un harbre po = bre y humilde).

(debido a su apariencia -pobre y humilde- no le hicieron caso)

en la cumbre de cada uno de estos montes altos llamodos Ten ten, había una culebra del mismo noribre

la culebra habló a los indios antes que saliese el mar, les dijo lo que iba a pasar y que subieran al cerro para librar se, porque ella los ampararía

los indios no creyeron y pensa ron que Tenten los quería enga ñar, ya que si ocurría la inundación se convertirían en peces (vallenos, pege espoda, lisas, robalos, atunes, pescados) y al no alcanzar la cum bre quedarían nadando en las aguas
En todas las provincias hoy algún Tenten y cerro de grande veneración, porque on él se salvaror los antepasados del Diluvio. Piensan que si hay otro Diluvio, volverán a salvarse chí, que es la misma presunción de los descendientes de Noé cuando fabricaron la Torre de Bobel.

siempre la soberbia humana desprecia la humildad $y$ no cree lo que no es conforme a su gusto

"que sin duda es el Demonio"

\footnotetext{
"que assi les engañaba el Demonio"
} 
en la tierra y en los lugares bajos había otra culebra llamada Caicai-Vilu

Caicai era enemiga de Tenten y de los harbres y para acabar los hizo salir el mar, pará anegar el cerro Tenten, la culebra de su nombre y los hom bres que trepasen a su cumbre

Caicai y Tenten luchan (compiten) entre sí:

Caicai hace subir el mar

Tenten levanta el cerro más al to que las aguas

al inundarse la tierra, los in dios suben al Tenten

los indios llevan consigo a sus hijos, mugeres y la comida que pudieron

muy pocos indios llegan a la cumbre del cerro

muchos fueron alcanzados por el agua antes de llegar a la cum bre y se convirtieron en peces

varios de ellos se convirtie ron en peñas, por su voluntod $y$ con ayuda de Tenten

como lo habían pensado

prueba de esto es una gran piedra en forma de mujer con sus hixos a cuestas

los indios que se transformaron en peces, después de la inunda- 
ción salían del mar y se relocio naban con las mujeres que iban a pescar o recoger mariscos y en gendrabon hijos en ellas, particulamente en las doncellas

los animales, por su mejor ins tinto y mejor conocimiento del clima (tiempo y sus mudanzas) su bieron muy rápidamente al Tenten y se salvaron en su cumbre

los horbres, debido a su incredu lidad, demonaron en allegarse al Tenten y fueron pocos los que llegaron a su cumbre

La mayoría de los harbres que llegó a la cumbre del Tenten, mu rió abrazada por el sol, ya que Tenten, en medio de la lucha con Kaikai, subió el cerro que llegó hasta el sol

los hombres, abrazados de calor, se cubrían con callanas y ties tos

a pesar de esto, muchos murieron debido a la fuerza del sol que estaba demasiado cerca

otros (hambres) quedaron calvos otros (hambres) se comín unos de aquí proceden los linajes: hay muchos con nombres de ballenas, lobos marinos, lisas y otros peces; ayuda a la creencia de los antepasados transformados en peces, haber visto sirenas que han salido a la playa lalgunos con hijos en brazos)

Caicai era como el demonio Tenten, "que era como cosa divina" (contradición con el comienzo, en que pensobo que era el Demonio) 


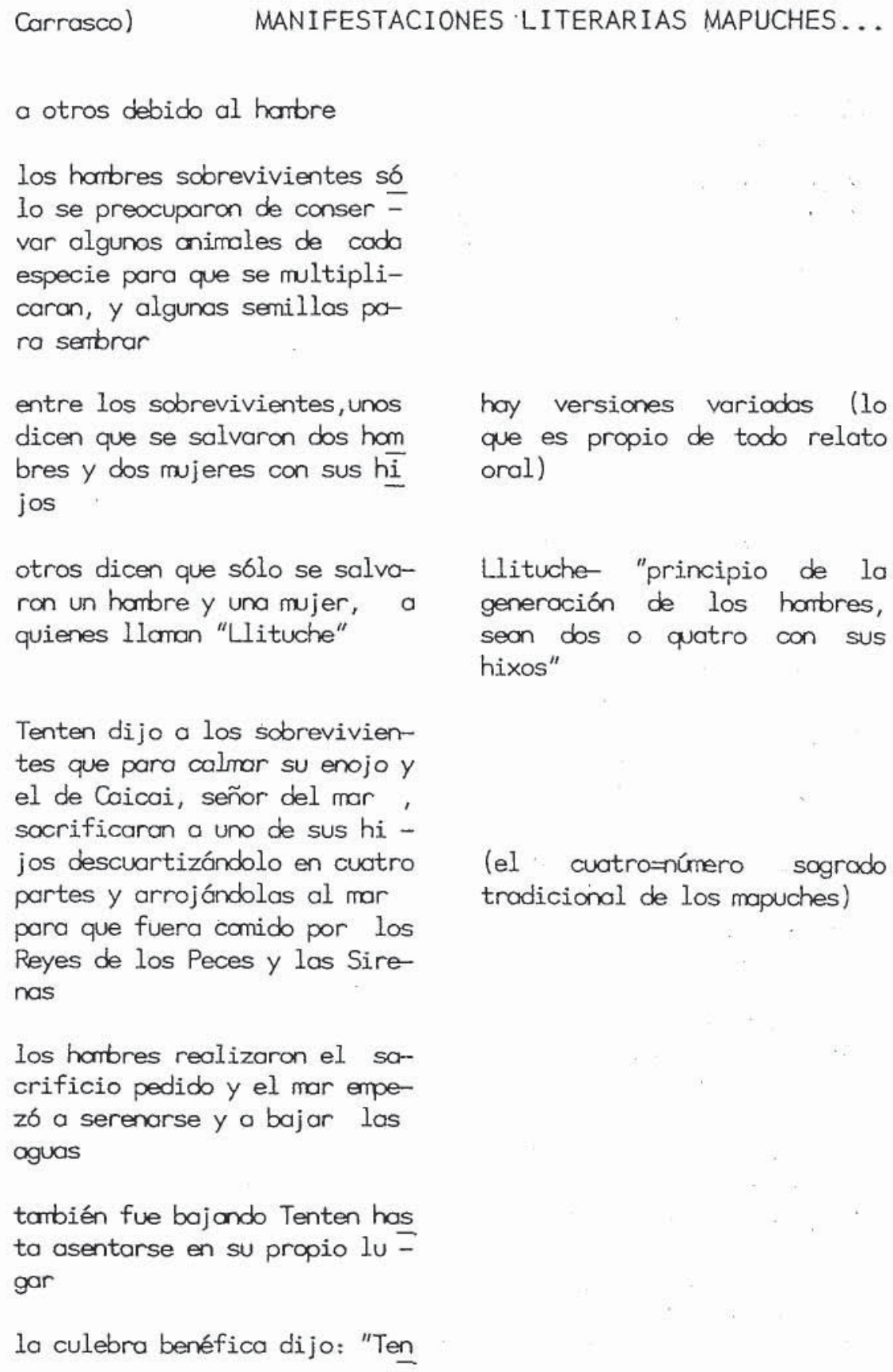


$\operatorname{ten}^{\prime \prime}$

desce entonces, la culebra y el esta astuta Culebra, que monte quedaron con ese nombre $y$ son grandemente respetados $y$ ve nerados entre los indios engañó a nuestros primeros padres en el Paraíso, desde entonces mantiene engañados corno a miserables a los indios de Chile.

\section{LA VERSION DEL P.ROSALES Y EL TEXTO ACTUAL DEL MITO MAPUCHE DE TRENTREN Y KAIKAI}

\subsection{El relato del diluvio en la etnoliteratura mapuche.}

Como ya se ha dicho, este relato así denominado por el P.Rosales, es una versión del mito de Trentren y Kaikai y, por lo tanto, se trata de un epeu mítico de gran importancia en la tradición mitográfica mapuche. Al contrario de lo que piensa Vicuña Mockenna (23), es un relato que nunca ha perdido vigencia. $\mathrm{Si}$ bien es cierto que ni Lenz, ni Augusta ni Guevara (24), lo incluyen en su colección de relatos, el P.Augusta se refiere explícitamente al mito e incluso en directa relación a la versión y opiniones del P.Rosales. Dice Augusta: "Encontramos el mito de Treng-Treng, ya en la historia del P.Rosales, aunque en una forma diferente. Mas de eso no se deduce que dicha forma sea la primitiva, y la nueva solamente adulteración de aquella antigua, pues es muy posible que en la época del citado historiador se contara el mismo mito con diversas variantes.

Esta leyenda tiene innegable analogía con el Diluvio, o por lo menos con el hecho de un diluvio universal, aunque no se ha tenido en cuenta el aspecto moral de éste.

Ha tenido lugar un diluvio, pero no tuvo relación con el pecadb. Esta es la creencia de los antiguos indios" (1934:235; el subrayado es nuestro). Por el propio Augusta sabemos que 
Tomás Guevara también conocía el mito, aunque en su Historia de la Civilización de la Araucanía prefirió presentar sólo un extracto del texto de Rosales (cfr. Augusta 1934:235-236).

En cambio, nuevas versiones del relato corno tal se encuentran en Saunière, Lehmann-Nitsche, Robles, Köessler-Ilg, Córdenos, Bahamondes y otros, Aravena y otros (25).

Un hecho curioso es que, aparte de la versión del P. Rosales recogida en Chile, las versiones más extensas y completas del mito han sido recogidas en Argentina. Dos de éstas, las obtenidas por Bertha Köessler-Ilg se relacionan directomente y en cierto modo forman parte del relato de los primeros días de la creación, en relación a la cual cobra sentido específico el mito de Trentren y Kaikai.

De acuerdo a mi experiencia personal de trabajo en terreno y a la de varios de mis colaboradores (26), este mito tiene plena vigencia en la actualidad, posiblemente en todo el territorio en que la cultura mapuche aún se mantiene camo tal, vale decir, desde Arauco por el Norte hasta parte de Osorno por el Sur, aunque es sabido que su centro de mayor concentración lo constituyen las provincias de Malleco y Cautín, que conforman la Novena Región de la Araucanía.

Las versiones actuales que conocemos son de índole muy variada en cuanto a su extensión, calidad discursiva y cantidad de información que contienen. No obstante y camo es obvio, todas mantienen la historia central básica, aunque varían o disminuyen los detalles e interpretan de varias maneras el relato, por lo general desde perspectivas ético-religiosas de orientación cristiana. Sin embargo, en muchos casos también, la historia se presenta desposeída de connotaciones religiosas cristianas.

Es importante observar que, al parecer, algunos aspectos del mito se han desprendido y transformado en historias míticas independientes. (Por supuesto, esto es imposible de probar en forma absoluta, porque también puede haber ocurrido al revés, es decir, que las versiones antiguas conocidas constituyeran un 
conjunto de relatós unidos por el narrador de la versión registrada). De todas maneras, los casos más notables se refieren a dos historias que, con mucha probabilidad, han surgido del episodio de los hombres que, por no alcanzar a llegar a la cumbre del Trentren antes de que subiera el agua, se convirtieron en peñas o en peces.

En el primer caso, se refiere que varios de estos hombres que fueron alcanzados por. el agua, se transfomaron en peñas "por su voluntad y con la ayuda de Trentren". Considerando las premisas del relato (castigo de la divinidad por su desobediencia - descuido, lo que trae cono consecuencia la transformación en piedra "viva"), éstas resultan idénticas a las que fundan el relato de Mankión, joven que es castigado por burlarse de la naturaleza (de orden divino para los mapuches, en su estado primordial) siendo transformado precisamente en una gran roca $\circ$ peña situada cerca de la playa.

En el segundo caso, se refiere que los hambres que se transfomaron en peces, "después de la inundación salían del mar y se relacionaban con las mujeres que iban a pescar o recoger mariscos y engendraban hijos en ellas, particularmente en las doncellas". Este episodio, casi con certeza, es el origen del mito de Sumpall, ser acuático sobrenatural, biforme (mitad hombre, mitad pez), que rapta y desposa a una joven que se halla cerca de la playa mariscando, recogiendo pescado $\circ$ bañándose. Incluso esto se confima por el hecho de que los hijos que Sumpall engendra en las jóvenes son, habitualmente, un lobito de mar, un choro $u$ otro ser acuático, lo que corresponde con la observación que hace el P.Rosales respecto a los linajes mapuches, muchos de los cuales tienen nombre de ballenas, lobos marinos, lisas $y$ otros peces.

El hecho de que de este relato-matriz se desprendan otros relatos que luego se independizon sin perder sus relaciones en el campo del universo mítico mapuche, es lo que nos ha llevado a pensar que el relato de Trentren y Kaikai constituye, en este sentido, uno de los mitos de origen de la cultura mapuche. Es evidante que este tipo de transformaciones ocurre no sólo a 
partir de un mito de origen, pero también debe considerarse que en este caso específico se trata de dos de los mitos de mayor vigencia en la actualidad. (27). De todos modos, esta observación debe corroborarse a otro nivel, considerando el contenido mismo del mito. En este sentido, no cabe duda de que el mito, a pesar de que no se refiere al nacimiento mismo del pueblo mapuche, detalla el "nuevo nacimiento" que significa el renacer de un pueblo después de haber sido azotado colectivamente por una catástrofe que lo deja reducido a unos pocos representantes. Esto es más notorio aún si se toma en cuenta que en la mayoría de las versiones conocidas la catástrofe se debe a un castigo divino al pueblo en conjunto $y$, en todos los casos, la lucha se establece entre las fuerzas del Mal (que significan la Muerte para los mapuches) y las fuerzas del Bien (que significan su Vida). El escenario cosmogónico de la contienda contribuye, a intensificar la grandeza del conflicto y sus connotaciones transhistóricas. En todo caso, es evidente que en torno a este problema sólo pueden formularse suposiciones razonablemente probables y de ninguna manera hacer afirmaciones absolutas, debido a la naturaleza del mismo y al hecho de no conocerse ( $\mathrm{ni}$ entre textos antiguos, $\mathrm{ni}$ en las versiones actuales) un verdadero "mito de origen" del pueblo mapuche, en el que figure con claridad el nacimiento de los primeros hombres y su desarrollo posterior. Esto no deja de ser curioso como asimismo el escaso interés existente al respecto, por lo que el mito recogido por el P.Rosales continúa siendo el más antiguo conocido y el que, a la vez, se ubica en una época más "antigua" en el ahistórico "Tiempo" del mito.

Claude Lévi-Strauss, que se ho preocupado de estudiar un aspecto de este relato (el origen de la calvicie, causado por Trentren al llevar a los hombres démasiado cerca del sol), no vacila en calificarlo camo mito de origen, Dice: "Pero, al recopilar las anteriores indicaciones, sólo nos proponíamos correlacionarlas con un detalle del mito de origen de los Araucanos, quentay que resumir ahora según las versiones publicadas y comparadas por Letmann-Nitsche" (28). Sin embargo, Lévi-Strauss no se detiene a fundamentar esta afirmación, ya que su interés es otro. Mús adelante, refiriéndose a la significación șimbólica de 
las fabulosas culebras del relato, agrega: "El estudio de los mitos sobre el origen de la cocina (...) nos condujo a concebir una oposición entre el mundo podrido que resulta de la disyunción del cielo y la tierra, y el mundo quemado que resulta de su conjunción. Para la mitología araucana estos dos mundos corresponden a los de Caicai y Tenten" (1970:154-155)(29). Seguir estas proposiciones de Lévi-Strauss nos alejarín del objeto de nuestro trabajo, planteado al comienzo. Por eso, volveremos a la versión del P.Rosales para compararla con otras actuales, desde el punto de vista secuencial.

3.2. El texto actual del mito: cuatro versiones.

Enpleando cuatro versiones relativamente actuales (1979 y 1980, cfr. Anexo) del mito, elaboraremos el enunciado secuencial del relato para, más adelante, compararlo con la versión del P. Rosales.

Versión 1

En tiempos muy remotos llovió mucho

el tiempo estaba my malo

\section{Versiones 2,3,4}

hubo un diluvio $(2$ y 4 ) koikoi envió mucha agua porque no creían en él (3) había truenos, relómpogos, temblores (3)

Trentren avisó a los mapuches que kaikai quería inundar la tierra $(2,3)$

un cerrito, trengtreng, cre cía a medida que el agua su bía

en la noche Kaikai gritaba "kaikai kaikai" y el agua
Trengtreng era la culebra del Bien (2) era un "pájaro" enviodo por Nguenechen (3)

eran dos bichos parecidos a un monstruo, parándose en las 


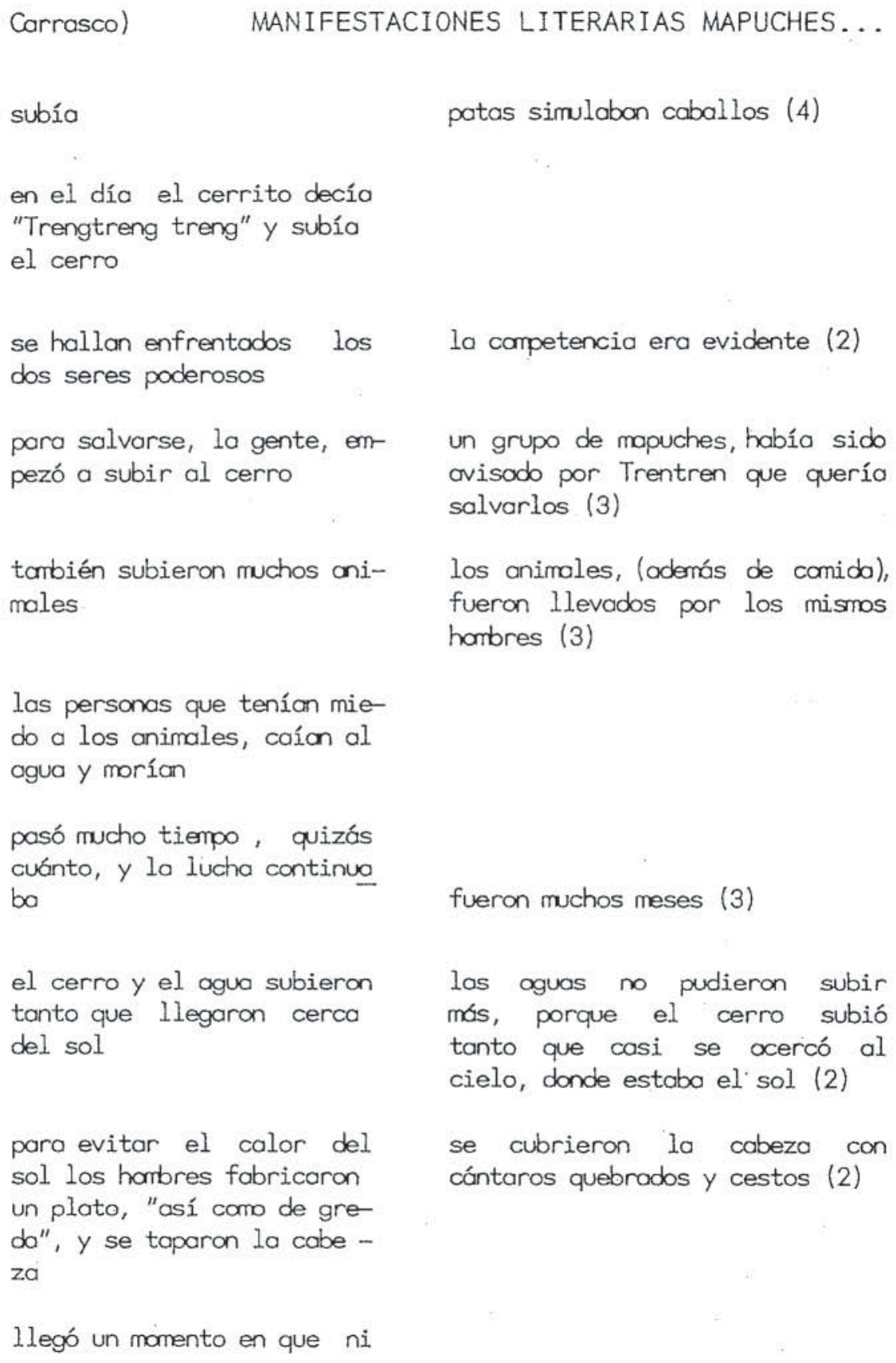


el cerro ni el agua pudie ron subir mós

después bajó el agua

se salvaron muy pocas perso nas

\begin{abstract}
debido al calor que allí reinabo (2)

cuando el agua bajó al nivel acostumbrado, la gente descendió y pudo sobrevivir (2) los que no alcanzaron a salvarse, fueron transformados por trentren en peces, cochayuyos, mariscos y otros elementos del mar que servirán de alimento a los mapuches (2)
\end{abstract}

con los pocos habitantes que se salvaron empezó a nacer de nuevo la población mapuche (3)

en la actualidad, los mapu ches construyen sus casas en los cerros.

Si hoy un nuevo diluvio, se salvarán de nuevo por el po der de Trentren.

Uha quinta versión, que no hemos incorporado, agrega sobre todo explicaciones e interpreta el sentido de los hechos y el valor de los personajes. Se titula "Caicai y Trentren" y literalmente dice así: "Se trata de Trentren. El Trentren es para salvarse los indígenas o quien sea, entonces tiene que decir "Trentren", eso es para salvarse. Dice "Caicai", eso es parc la ruina de toda la tierra, eso dice "Caicai". Puede venir 
del volcán o de cualquier otra parte el Caicai. Se le teme.

Para saber qué hora va a llegar, qué tiempo se va a anunciar por qué se va a anunciar, entonces se anuncia por tal parte; puede ser un espíritu u otra cosa. Anuncia el Trentren, anuncia el Caicai. Se anuncia por la paisana o la veterana.

Es por eso que se supo que llegó el oviso del Trentren, el aviso del Caicai. Se salvó la parte del hambre, así es que por eso está tranquilo el mundo, dice el cuento, si no, esto no fuera tierra" (Mariano Segundo Millahual Lemunao. Quetrileufu (Pucón), 1980 (30).

\section{COMPARACION DE LA VERSION DEL P.ROSALES Y LAS VERSIONES ACTUALES}

La comparación entre la versión del mito de Trentren y Kaikai anotada por el P.Rosales y las cuatro versiones actuales escogidas no pretende ser exhaustiva, ya que se realiza en un solo nivel posible: el de la historia. El nivel discursivo (31) - del relato y la narración (32), no pueden ser estudiados con validez, debido a que uno de los términos de comparación (la versión del P.Rosales) carece de materia escritural propiamente narrativa $y$, desde luego, no es presentado en forma directa por los hablontes originales.

Por otra parte, en un primer momento, la comparación se centrará en las variantes encontradas al contrastar la secuencia de la VR (versión Rosales) y la matriz secuencial de las VA (versiones actuales) (33), entendidas en dos sentidos: a) variantes por oposición, es decir, cuando ambos textos presentan un mismo trozo de la historia de manera diferente; y b) variantes por presencia/ausencia, es decir, cuando uno de los textos presenta un aspecto de la historia que el otro no objetiva mediante el discurso.

En un segundo momento, la comparación se centrará en los mamentos en que aparece en el discurso narrativo la conciencia 
exegética del autor de la VR, vale decir los momentos en que el P.Rosales "comenta" el mito mapuche desde la perspectiva de "otra conciencia" indudablemente no-mapuche. Se trata, en particular, de intercalociones de estructura sentenciosa, relativas a la función que atribuye al relato histórico y mítico.

A continuación, proponemos un esquena comparativo $V R$ y VA, designando con números las variantes por oposición y con letras minúsculas las variantes por presencia/ausencia, ejecutando en seguida la lectura correspondiente ( $v$ ), v2, v3, etc. y vo, vb, vc, etc.)

\section{R}

1. salió el mar

a. cerros eran sagrados

2. un hambre de apariencia humilde avisó a los mapuches

3. en cada monte había una culebra llamada Tenten

b. Trentren "profetiza" lo que ocurrirá

d. los indios temen conver tirse en peces

4. varios hombres se con vierten en peños ( por su voluntad y con ayuda de Trentren)

f. indios-peces se relocio
V A

lluvia, tempestad, diluvio

Trentren avisó a los mapuches

un cerrito llamado Trengtreng (y también la culebra)

c. características de las culebras: parecían caballos

e. las personas que temen a los animales caen al agua y mueren

Trentren los transforma en peces, cochayuyos, mariscos $y$ otros 
nan con mujeres $y$ engen dran hijos

g. animales se salvan gracias a su instinto

h. hombres se pierden debi do a su incredulidad

i. muchos hambres mueren debido a la fuerza del sol

5. para evitar el calor se tapan con callanas y se tapon con cántaros quebratiestos

j. canibalismo circunstancial: algunos horbres se comían a otros dos y cestos

k. el agua baja por el calor reinante

1. sobrevivientes conser van animales de cada es pecie $y$ semillas (eran dos hambres y dos mujeres con sus hijos, o un harbre $y$ una mujer)

m. Trentren pide un sacrificio humono, el que es efectuado

Las variantes por oposición. Corno puede verse, las variantes por oposición no son muchas, sólo cinco, y la diferencia no es demasiado importante, más bien se complementan entre sí. En el primer caso (vl), la diferencia mar/lluvia, tempestad/diluvio, es reductible a una categoría superior: agua, elemento que 
en la simbología mapuche tiene diversas connotaciones, por lo general negativas cuando se trata de líquido espeso $u$ oscuro, removido con violencia, o en cantidad excesiva.

En el segundo caso (v2), la diferencia reside en que el ser sobrenatural envía un representante para avisar a los hombres del desastre que se avecina o bien se comunica directamente con ellos. Esto sin duda muestra, en el primer caso, una separación entre el mundo sobrenatural y el mundo humano, fuertemente jerarquizado a fovor del mundo sobrenatural, lo que requiere la necesidad de un mediador 0 intermediario. En el otro caso, mundo sobrenatural y mundo humano se hallon estrechamente relacionados entre sí y no requieren de intermediario, lo que concuerda mejor con la cosmovisión mapuche.

La variante $3(\mathrm{v} 3)$ es de gran importancia y muestra la movilidad permanente entre procesos metonímicos y metafóricos, tan camunes al pensamiento mítico. En un caso se trata de un cerro en el cual se halla una culebra llamada Trentren, es decir, dos elementos, diferentes relocionados por extensión del tipo parte a todo, ya que la culebra es parte del cerro. En el otro caso, cerro y culebra se hallan fundidos en un solo ente, mezclando elementos diversos (mundo natural y mundo zoológico, alto y bajo, inerte y vivo, estático y en movimiento) en una nueva realidad multidimensional al modo metafórico. Por otra parte, oponiendo los dos conjuntos entre sí, se puede observar el doble proceso metonímico-metafórico en el hecho de que al interior de un conjunto se establece una relación por extensión (la culebra es continuidad del cerro, y viceversa), que luego se transforma en una relación de sustitución (al transformarse los dos elementos yuxtapuestos en una fusión de ambos = monte-culebra).

La variante 4 ( $\mathrm{v} 4$ ) presenta a varios harbres convertidos en peñas, debido a su voluntad en un caso y en el otro debido a la voluntad de Trentren, lo que plantea por un lado la participación del harbre en eventos que demandan poderío sobrenatural y en el otro la subordinación del hambre a la divinidad, problemas ambos que se refieren también al de la libertad y autodeteminación humonos. Por otro lado, la variante muestra la oposición 
piedra (mundo natural terrenal, inerte, imóvil) versus peces, cochayuyos, mariscos (mundo zoológico acuático, vivo, en movimiento), elementos que se hallan estrechamente relacionados en un ambiente marino, lacustre 0 de grandes ríos y que, con mucha frecuencia también, se funden entre sí. De nuevo, la fusión de realidades heterogéneas eliminando las fronteras o límites entre unos $y$ otros.

La última variante por oposición (v5) se refiere a los distintos elementos que los hambres emplean para protegerse del. calor excesivo del sol, en un caso callanas y tiestos, y en el otro, cóntaros quebrados y cestos. A pesar de que la función que cumplen es la misma, no puede dejarse pasar la diferente naturaleza de los elementos y la diversa función que cumplen en la cultura mapuche. La callana es un artefacto cultural, construido por elementos en gran medida artificiales, que se usa para preparar la harina tostada, elemento fundamental en la cocina mapuche. Tiene conexiones con el fuego y se relaciona de modo horizontal con los tiestos, donde se puede presumir que se guardan alimentos. En cambio, el cántaro, artefacto también cultural, más cercano por su constitución a la tierra y al agua, pero también al fuego, se mueve en el ámbito de lo ritual y lo sagrado. En efecto, el cántaro se halla en el rehue de la machi y se emplea en la mayor parte de las ceremonias religiosas, por lo general para contener el mudai sagrado que se asperja en diversas direcciones sobre la tierra. El cesto, muy probablemente se trata de un llepu, artefacto extendido y casi plano fabricado de junquillo - ñocha, que con frecuencia complementa la función del cántaro, guardando los alimentos $u$ otros alimentos no líquidos que se usan en las ceremonias religiosas. Como puede verse, la relación de estos dos últimos artefactos es también de correlación complementaria horizontal. Comparando ambos conjuntos, puede establecerse que el último responde de manera más coherente a la connotación religiosa, de relación entre mundo natural y sobrenatural en que se sitúa el acontecimiento.

Las variantes por presencia/ausencia. La VR presenta diez variantes de esta clase, mientras que las VA presentan sólo tres, lo que ya muestra la mayor extensión y complejidad de la 
primera.

Las variantes de VR pueden reunirse en tres grupos. El primer grupo, más numeroso que los otros, se puede reconocer por la connotación religiosa o sobrenatural que las reúne y que es, por otra parte, una de las constantes del relato mítico. En la primera de estas ( $v a$ ) variantes, se explicita el hecho de que los cerros son sagrados (afimación imecesaria para una conciencia mapuche, que lo sabe o lo presupone); en consecuencia, con este atributo, vb indica cámo Trentren augura lo que sucederá a futuro. La vf se refiere a un hecho que excede los límites de la naturaleza humana y que reitera la relación imediata existente entre realidad natural y sobrenatural: los mapuches transformados en peces (seres sobrenaturales) se relacionan con mujeres humanas y engendran hijos. Estos, de acuendo al pensamiento mítico mapuche manifestado en otros relatos, deberán ser de forma híbrida humano-animal o animal-humano y de naturaleza sobrenatural (como sucede por ejemplo, con el hijo en forma de lobito de mar, choro $u$ otros seres acuáticos, que a la vez poseen atributos humanos, que es engendrado por Sumpall y su esposa humana). La wh connota claramente la importancia de la fe religiosa, ya que su ausencia es el motivo que lleva a la muerte a los hambres. Se relaciona directamente con $\mathrm{vl}$, en el sentido de que ambas se proyectan teniendo como punto de referencia el relato bíblico del Diluvio Universal (que esto sea coincidencia $\circ$ influjo directo 0 indirec to, no es problema atingente ahora), aunque al mismo tiempo la situación básica de la mantención de una pareja humana, que constituirán el "nuevo pueblo" ligado positivamente a la divinidad luego de la extinción de la especie, es también común a muchos otros mitos de origen. Incluso en este caso se dan dos posibilidades: pueden ser dos hambres y dos mujeres, es decir, cuatro (número sagrado de los mapuches), tétrada que se corresponde con la que encabeza el ponteón mítico mapuche. La última variante de este grupo, $\mathrm{m}$, apunta a un hecho que al parecer en la antigüedad era común: el sacrificio humano. para aplacar a la divinidad negativa, y cuya fuerza ancestral renace en ocasiones de grandes catástrofes, camo sucedió en las cercanías de Puerto Damínguez durante el maremoto de 1960. (Una antigüedad no resuelta del todo en el texto de VR es si el sacrificio 
es pedido cano expiación de la mala vida anterior llevada por los mapuches, lo que sería un ocatamiento de la voluntad de Trentren -más exactamente de Ngënechen-, o una fórmula de aplacamiento de la posible cólera futura de Kaikai, es decir, de los wekufü).

El otro grupo de variontes se caracteriza por explicar el motivo oculto $\circ$ la intencionalidad que motiva $\circ$ trasciende un hecho. Así, por ejemplo, en vd se muestra el temor de los mapuches por ser transformados en peces; en vg se explica por qué los animales se salvan, a diferencia de los hombres, lo que también se explica en wh (yo comentada), que es el término complementario de la oposición; y en vi se detalla la razón exacta de por qué el sol produce la muerte de los hombres.

El tercer grupo (en realidad formado por una sola variante, vj), muestra in hecho que podría ser de interés para los etnólogos, pero cuya explicación no presenta mucha evidencia en otros relatos conocidos: el canibalismo, situación mostrada en este texto como absolutamente circunstancial e incluso exigido de manera casi forzosa por las circunstancias.

Como se dijo al comienzo, es evidente que el primer grupo de estas variantes no sólo es cuantitativamente más significante, sino que tarbién de mayor interés e importancia, tanto en el texto mismo como en su correlato referencial.

Tal vez por la razón ya indicada (de que la conciencia mapuche considera innecesario explicitar lo que para ella es sabido $u$ obvio), las tres variantes de VA son meramente explicativas de situaciones puntuales. La vc, señala de manera figurada una característica de las culebras sobrehumanas: son tan enormes, tan fuertes y activas, se levantan tanto, que parecen "caballos". La ve, de manera similar al segundo grupo de VR, explica que las personas caen al agua y mueren debido al temor que tienen a los animales (situación comparable a la de las personas que pudieron. temer vivir con animales en sus rukas, o atravesar un río en una balsa en que van agrupados indistintamente horbres y animales, corno todavía ocurre, por ejemplo, en la balsa de Boca-Budi). Por 
último, vk explica también que el agua baja debído al calor reinante, al haberse aproximado en tal medida la tierra inundada al sol quemante.

A continuación, proponemos un segundo esquema que no intenta resumir todo el relato mítico (ya presentado), sino únicamente los momentos del decurso narrativo en los cuales surge la conciencia crítica del hablante no-mapuche, que explica y comenta los hechos que reseña desde su propia perspectiva, creencias religiosas y cultura. Para ser ecuánimes en la valoración, hay que tener en cuenta que, si bien el P.Rosales discrepa con muchos de los acontecimientos que anota, no por eso deja de presentarlos previamente, de modo que el lector posible puede extroer también su propio juicio al respecto.

\section{Texto de la tradición}

a. antiguamente salió el mar y se anegó la tierra

1. Los mapuches huyeron a refu giarse en los cerros (Ilama dos Trentren o donde habita ba una gran culebra de ese nombre)

2. un hombre de apariencia pobre y humilde avisó a los mapuches de que iba a ocu rrir el Diluvio o salida de mar, debido a su apariencia no fue escuchado

\section{Comentario}

no se sabe cuándo ocurrió; debido a que los mapuches no cuentan con medidas de tiempo

en todas las provincias hay Tenten, my venerados porque en él se salvaron los antepasados sobrevivientes del Diluvio Universal.

Si hay otro Diluvio, piensan que volverón a salvarse chí (la misma presunción de los descendiéntes de Noé cuando fabricaron la Torre de Babel)

siempre la soberbia humana desprecia la humildad y no cree lo que no es conforme a su gusto 
3. en la cumbre de cada monte alto había una culebra lla mada Trentren ( al igualque el monte); o bien, (1o más generalizado más ade lante) una sola gran culebra llamada Trentren

4. los mapuches no creyeron a Trentren o a su enviado cuando les previno de la catástrofe que se avecinaba e invitándolos a subir a la cumbre del cerro, te miendo ser convertidos en peces

5. muchos mapuches fueron alcanzados por el agua antes de llegar a la cumbre del cerro Trentren y se convir tieron en peces

b. varios de ellos (por su vo luntad y con ayuda de Tren tren) fueron convertidos en peñas

c. Ios mapuches transformados en peces, terminada la i nundación, salían del mar, se relacionaban con muje res $y$ engendraban hijos en ellas

6. La mayoría de los harbres que subió a la cumbre de Trentren, murió quemada cuando el cerro se aproxi- "que sin duda es el demonio"

"que assi las engaña el Demonio"

así como lo habían pensando

prueba de esto es una gran piedra en forma de mujer con $\therefore$ sus hijos a cuestas

de aquí proceden los linajes (nombre de ballenas, lobos marinos, lisas otros peces); ayuda a esta creencio el hecho de haberse visto sirenas en la playa, algunas cor sus hijos en brazo.

Kaikai era como el Demonio y Trentren era "como cosa divina" 
mó demasiado al sol

d. entre los sobrevivientes al gunos afiman que se salvaron dos parejos con sus hijos; y otros sólo una pareja, harbre y mujer a quie nes llaman "Llituche"

7. desde entonces ( terminada la contienda entre ambas cu lebras), la culebra y eI monte quedaron con el nom bre de Trentren y son muy respetados y venerados por los mapuches

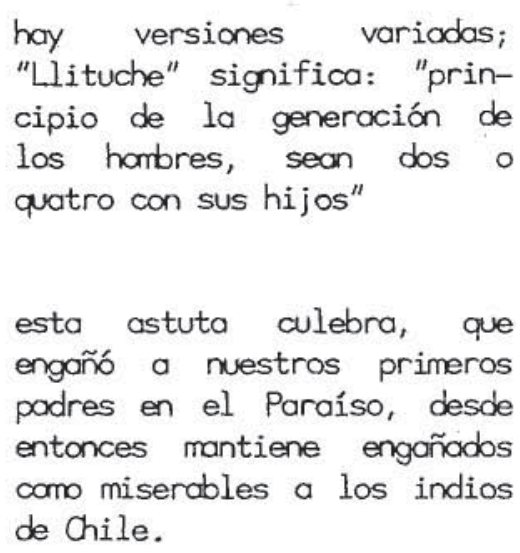
"Llituche" significa: "principio de la generación de los hombres, sean dos o quatro con sus hijos"

esta astuta culebra, que engañó a nuestros primeros padres en el Paraíso, desde entonces mantiene engañados camo miserables a los indios de Chile.

Como puede observarse, los comentarios del P.Rosales son bastante numerosos, lo que no puede extrañar ya que se trata de un texto extenso y complejo y procedente de una cultura muy diversa a la del estudioso que lo registró. Sus observaciones pueden agruparse en dos conjuntos no muy definidos entre sî, diferentes $y$, en cierto modo, complementarios. Uhas pretenden ser explicaciones histórico-etnográficas, y los otros son claramente comentarios religioso-morales, aunque en oportunidades ambos conceptos se mezclan entre sí. Entre las explicaciones histórico-etnográficas, se encuentra la primera de sus observaciones ( $\mathrm{Ca}$ ), donde el P.Rosales, con evidente criterio de historiador intenta situar en el timpo el hecho que comenta, lo que no consigue debido a que el texto no lo consigna y él ignora la manera en que los mapuches medían el tiempo. Así, elabora una explicación que le exige su propia lógica cultural: si los mapuches no han determinado la fecha o seriación cronológica de los hechos, es porque carecen de medidas de tiempo. Aparte de observarse aquí el tributo que el Padre paga a su cultura y a su "deformación profesional", se nota también que ha olvidado la naturaleza del texto que presenta. En otras palabras, está obviondo que se trata de un mito, que por norma no establece ningu- 
na precisión temporal, sino que le basta con una fómula amplia y vaga ("antiguamente"...), y está observando el texto como un discurso veraz. Esta misma actitud continúa en $\mathrm{Cb}$, en donde busca la relación directa entre un objeto observable en la realidad y un enunciado del discurso mítico; dirá, incluso, que este último puede ser "probado" por la existencia de aquél (una piedra en forma de mujer con sus hijos, probaría la transfomación de algunos mapuches en peñas). Esta forma de explicación causal directa, es, aparentemente, muy corriente entre algunos narradores o informantes, que intentan atestiguar la veracidad de lo relatado poniendo ejemplos tomados de la realidad física (el caso de la famosa "piedra Mankián", en el sector del Budi Puerto Sacridera (p.ej.) o de su propia experiencia. No obstante, lo que hacen no es explicar el hecho en sí mismo, sino, como se ha dicho, "ejemplificar" con casos análogos. Y también algunos estudiosos antiguos (como Latcham, entre otros) y algunos investigadores actuales, tratan de reducir la significación de un relato mítico a la mera relación más o menos directa entre el enunciado verbal y la situación etnográfica, olvidando el sistema simbológico de que forma parte y en que se mueve el mito. La misma relación causal (en este caso más atendible, porque se establece entre una creencia y sus consecuencias en la cultura) se puede ver en $\mathrm{Cc}$, cuando el Padre destaca los numerosos linajes que toman el norbre de seres marinos o acuáticos, observaciones de gran agudeza e interés en relación a un pueblo que se autodefine como "gente de la Tierra" y que carece de tradiciones marineras. A esto le ayuda su manejo de la lengua y las informaciones que maneja al respecto. No obstante, en la segunda parte de su explicación, vuelve al criterio anterior, al relacionar causalmente el hecho de haberse visto sirenas en las playas (que él afima que es verídico) con el otro hecho no menos fabuloso de hombres transformodos en peces que engendran hijos en hombres humanos. Como atenuante, debe sí tenerse en cuenta que ambas situaciones son muy similares y de una misma naturaleza, y que si una de ellas es verdadera (como él lo afima) es de toda lógica pensar que la otra similar también lo sea.

En la explicación Cd, se corrobora la suposición de que el texto presentado por el P.Rosales es producto de un conjunto 
de versiones que él reunió y sintetizó en una sola. Esto denota también la naturaleza discursiva del texto: se trata de un relato oral, una de ayyas características definitorias es su modo de existencia disperso en innúmeras versiones complementarias y que encuentran su sentido en el sistema que simultáneamente conforman y las abarca. En la segunda parte de la explicación, se demuestra una vez mós el afán de veracidad y exactitud del historiador, que hace uso de las explicaciones existentes en la propia lengua y. cultura estudiodas.

Los comentarios religioso-morales se ordenan en especial al análisis de elementos religiosos mapuches observados tanto en el sisterma de su propia cultura como en comparación a las creencias cristiano-católicas de la época, desde la cual son evaluados. Así en $\mathrm{Cl}$ explica el Diluvio o catástrofe relatada por los mapuches entendiéndola desde la perspectiva del Diluvio Universal relatado en la Biblia y comparando explícitamente a los sobrevivientes que alcanzaron a subir a los cerros (o al cerro) Trentren con los hambres y mujeres salvados en el arca de Noé. De esta manera, la correlación es exacta: Cerro Trentren = arca de Noé, lo que con un criterio de pensamiento homólogo resulta incuestionable, aunque pueda ser cuestionada su veracidad histórica. Esto es de gran interés si se observa que el P.Rosales siempre que se enfrenta a realidades naturales (e incluso a veces a algunas poco claras), intenta explicarlas de acuerdo a sus principios y métodos de historiador, tratando de buscar evidencias fácticas o documentales o el testimonio de experiencias cercanas. En cambio, cuando se enfrenta a hechos sobrenaturales, aunque en ocasiones recurre a elementos evidenciales que le parecen apropiados, por lo general adopta otra forma de pensamiento diferente, más acorde con la consecuencia lógica de verdades reveladas que con la experiencia imediata. En este sentido, su pensamiento se muestra diferente, como era razonable suponer, al pensamiento mapuche que interrelaciona mundo natural y sobrenatural de una manera distinta.

El $C$ es una suerte de disposición moral, conforme a la tradición cristiona.y una severa crítica cultural. C3, C4 y C5 son observaciones que tratan de interpretar los hechos relatados 
desde una perspectiva cristiana, lo que le hace confundir en un primer momento a Trentren con el Demonio, al presentarse ésta camo una culebra que vaticina el futuro $y$, a su juicio, pretende engañar a los mapuches. Esta opinión es corregida en C6, donde distingue con mayor exactitud que Trentren simboliza el Bien (por lo que la compara con "cosa divina") y es Kaikai quien es comparable con el demonio. Cabe destacar que en ambos casos recurre a la comparación, indicando con esto la serejanza, pero sin emplear en ninguno la metáfora, que habría significado en cierto modo la identificación de ambas realidades. Sin embargo, el C7 vuelve a la forma de razonamiento anterior, en que el Padre, interpretando desde la perspectiva de su fe la realidad de una cultura ajena, insiste en la comparación de Trentren con el demonio. No obstante, hay dos aspectos que en cierto modo explican esta contradicción e insistencia: es de nuevo el aspecto de Trentren (similar a la forma de culebra que tomó el Demonio en el paraíso para engañar a los primeros hambres y sobre todo ahora el hecho de ser Trentren respetado y venerado como una divinidad (tanto la culebra camo el monte del mismo nambre), lo que sin duda choca con sus convicciones religiosas en las cuales sólo cabe adorar a Dios y venerar a los santos, nunca a los seres naturales o humanos en cuanto tales.

Estos comentarios y observaciones podrían aún extenderse y ampliarse; no obstante, nos parecen suficientes para el objetivo que se pretendía. Conviene, por último, reiterar de todos modos que en el análisis hecho se han considerodo sólo algunos aspectos, precisamente aquellos que sirven al P.Rosales para comentar desde su punta de vista el texto mapuche intercalando trozos discursivos que petenecen a una conciencia ajena $y$ disímil al discurso que comenta. No obstante, en justicia debe reconocerse que, ante todo, se preocupó de dar a conocer el texto mítico en la forma más fiel y completa posible, lo que consiguió en un grado que con mucha dificultad se puede encontrar en investigadores coetáneos o posteriores a él preocupodos de la misma área de estudio. 
CULTURA, HOMBRE， SOCIEDAD

(3.1.1986

NOTAS:

(1) P.Bernardo de Hovestadt: Chilidúg'u, sive Res Chilenses. Monasterii Westphaliae, 177, 2 tomos (cfr.párrafo 411)

(2) Francisco Nóñez de Pineda y Bascuñán: El cautiverio feliz. Santiogo, Zig-Zag, Biblioteca de escritores de Chile, 1948; Discurso Quinto, cap. XII, pp.403 y 404.

(3) Dice: "Y para que se reconozca que en sus joviales voces, algunos de sus romances constan de medidas sílabas, pondré la letra que cantaban" (Cautiverio, 403). Esto es muy discutible, aunque casualmente puede ocurrir. Angel Gustodio González acepta la afimación de Pineda y Bascuñán, incluso atribuyéndole que descompuso con sus sílabas los versos, lo que no es exacto, ya que se limitó a transcribir el texto, decir que posee una métrica regular y luego traducirlo a una estrofa hispánica común en la época. Con escaso conocimiento de la lengua mapuche. A. Uustodio González efectúa él la separación silábica de los versos en la forma que supone acertada (cfr. "Introducción" al Cautiverio, pp. 55-56).

(4) Resulta curioso que con el dominio de la lengua y la cultura mapuches que demuestra Pineda y Bascuñán, no haya empleado la denominación existente en mapudungun, es decir, ülkatun o ülkantun, y haya preferido la española de "ramance". Sin duda lo hizo pensando en los probables lectores, familiarizados con este tipo de nomenclatura y porque, sin duda, ambos tipos de discurso (aunque de culturas distintas), tienen algún parecido. No obstante, el ülkatun se asemeja más que al romance propiamente tal, a ciertas composiciones líricas de circunstancias, que desechan el modo narrativo para expresar con gran libertad métrica los sentimientos actuales y momentáneos del hablante individual y no del de la comunidad.

(5) All referirse a esta obra manejamos la siguiente edición: 
R.P.Diego de Rosales: Historia General de el Reyno de Chile, Flandes Indiano. Valparaíso, Imprenta del Mercurio, 1877-78. Diez libros distribuidos en 3 tomos. Publicada, anotada y con una biografía del autor por Benjamín Vicuña Mackenna.

Existe también una antología preparada por la Editorial Universitaria, con fines de divulgación.

(6) "Vida de Diego de Rosales", en Historia, cit. p.XXXIII.

(7) Juan Adolfo Vózquez: "El compo de las Literaturas Indígenos Latinoamericanas" en Revista Iberoamericana, 104-105, Julio-Diciembre, 1978, Vol.XLIV; pp.313-349.

(8) "Estas áreas incluyen documentos indígenas conservados en su lengua original, tempranos informes europeos ocerca de tradiciones literarias indígenas, literatura popular moderna de América Latina influida por tradiciones Indígenas, y literatura hispanoamericana contemporánea que recrea visiones del mundo americano aborigen" (1978:313).

(9) Iván Carrasco: "Notas introductorias a la literatura mapuche" en 3a. Semana Indigenista, vol. colect. de Carrasco, Hidalgo, Salas y Stuchlik, Tenuco, Ediciones Universitarias de la Frontera, nov. 1972: pp.15-23.

(10) Iván Carrasco: "En torno a la producción verbal artístico de los mapuches "en Estudios Filológicos 16. Valdivia, 1981; pp.79-95. Facultad de Filosofía y Humidades, Uhiversidad Austral de Chile.

(11) Fernando Lózaro Carreter: Estudios de Lingüística. Barcelono, editorial Crítica 1980. Cfr. en especial "El mensaje literal", pp.149-171; "Lengua literaria frente a lengua camún", pp.193-206; "Literatura y Folklore: los refrones", pp.207-217.

(12) Dice Lázaro Carreter: "Nuestra división funcional del 
lenguaje permite considerar la literatura oral o escrita como manifestación (no única, según vermos) del lenguaje literal. El hecho de que el folklore literario ofrezca multitud de variantes como accidentes de su transmisión, no lo exime de obedecer a los mecanismos de la lengua literal" (1980; 160, el subrayado es nuestro).

Merecen discusión dos hechos. a) no distingue entre versión y variante, b) considera la existencia de variantes sólo corno "accidentes de transmisión", siendo que éste es uno de los rasgos distintivos del relato oral.

(13) Desde luego, aquí ni siquiera intentamos dbordar la naturaleza del mito, problema largamente estudiado desde perspectivas y disciplinas distintas y aún opuestas, y que todavía no ha sido resuelto en forma plenamente satisfactoria. Por eso, sin entrar a discutir ninguno de los múltiples estudios existentes (Eliade, Cassirer, Jung, Lévi-Strauss, etc.), sólo pretendemos una descripción somera del mito como discurso, que sea funcional y operativa para este trabajo.

(14) El término etnoliteratura es tributario del de etnoestética manejado por María Ester Grebe en "Etnoestética: un replanteamiento antropológico del arte" en Aisthesis 15. Santiago, 1983, pp.19-27. Instituto de Letras, U. Católica. (Cfr. tb.el Diccionario Razonado de Semiótica, de Greimás-Courtés. Madrid, Gredos, 1983.

(15) Cfr. al respecto Hugo Carrasco: El Mito de Shumpall en relatos orales mapuches. Tesis para optar al grado de Magister en Literatura, Facultad de Filosofía y Humanidades, Universidad Austral de Chile. 1981.

(16) Cfr. Hugo Carrasco: "Sobre la noción de relato oral mapuche" en Actas del Tercer Seminario Nacional de Estudios Literarios. SOCEL-USACh Facultad de Estudios Generales, Depto. de Idiomos, 1983; pp.236-247. 
(17) En el Libro Segundo también hay observaciones sobre el particular. Entre los más interesantes se hallan las notas sobre las sirenas 2:22, sobre las piedras de sacrificio de niños $2: 2$, sobre piedras varias $2: 5$, sobre ríos $y$ fuentes $2: 12$, y otros.

(18) Guriosanente, Ivón Carrasco ha alegado esta característica, la "hibridez estructural", como una de las propiedades definitorias del discurso verbal artístico mapuche (cfr. 1972: 20-23), lo que mostraría indirectamente hasta qué punto el P.Rosales ha internalizado algunas de las pautas mentales y culturales mapuches.

(19) "Y lo que hace más insuperable la dificultad de conocer su origen, es no hallarse entre los Indios occidentales historias, libros, tablas, pergaminos, cortezas, bronces, mármoles, columas, medallas, epitafios, inscripciones, cifras, caracteres, nudos de ilos de donde poder tinar para salir de este laberinto, ni otra materia ni arte con que conservar las materias antiguas" (Libro Primero: 2).

(20) En relación al desconocimiento de la multiplicación de los harbres después del Diluvio por los pueblos indígenas, es curioso el caso del Papol Vuh, que sí parece conocerlo (lo que demostraría su reescritura cristianizante). Respecto a los "sueños", es interesante recordar que los mapuches reconocen un modo especial de sueño (peuma, o peumatun), que otorga un conocimiento privilegiado, al parecer adivinatorio o profético, de la realidad.

(21\% "Sólo tienen algunos varruntos de el Dilubio, por haberles dexado el Señor algunas señales para conocerle; y aunque de el no tienen noticia: cierta ni tradición, por las señales coligen averles avido" (Libro Primero: 3).

(22). "Traxe con admiración algunas de estas conchas convertidas en piedras, para ablandar los corazones de piedra de 
los Indios"... (id anterior). Puede observarse la imoginación metafórica y el sentido poético de la composición que en ocasiones alcanza el Padre.

(23) "Las curiosas revelaciones que Rosales obtuvo personalmente de los indios, i que hoi dia están completomente estinguidas en su memoria"... (Nota (1) al Cap.I del Libro Primero de la Historia General, del P.Rosales, p.7).

(24) Rodolfo Lenz: Estudios Araucanos. Santiago, Imprenta Cervantes, $1895-97$.

Fray Félix de Augusta: Lecturas Araucanas. Padre Las Casas, Imprenta y editorial Son Francisco, 1934 (1910). Incluye los "Textos recogidos por el R.P.Fray Sigisfredo de Franhavesl".

Tomás Guevara: Folklore Araucano. Santiago, Imprenta Cervontes, 1911.

(25) Sperata de Sauniére: Quentos Araucanos y Chilenos. Santiogo, Nascimento, 1975.

Roberto Letmann-Nitsche: "El diluvio según los araucanos de la Pampa" en Revista del Museo de la Plata. N' 24(II), t.12, pp.28-62. Eulogio Robles Rodríguez: "El Coy Coy y el Trentren" en Costumbres y creencias araucanas. Santia9o, Ediciones de la Universidad de Chile, 1942; pp.55-57. Bertha Koessler-Ilg: "El Dios del cielo y sus rebeldes hijos" y "Sobre Adán y Eva" en Guentan los Araucanos. B.Aires, Losada, 1954; pp.13-15 y 16-18.

Antonio Cárdenas T.: "Peleco, el cerro de tres patas" en Leyendas Mapuches. Rancogua, Editorial Brecha, 1975, pp.11-12. Alicia Bahamondes y Otros: "El Trengtreng y el Kaikai" y "El Diluvio" en Recopilación y análisis de algunos relatos orales mapuches de la Región de la Araucanía. Seminario conducente al Título de profesor de Estado en Castellano. Temuco, Universidad de Chile, 
1979; pp. 82-83-84.

Aravena y Otros: "La guerra" y "Trengtreng: crecer y crecer" en El relato mítico mapuche. Seminario conducente al Título de profesor de Estado en castellano. Tenuco, UFRO, 1983.

(26) Me refiero especialmente a los proyectos sobre Recopilación y análisis de epeu (1980-83) y El relato mítico mapuche (1984-86) y a los diversos Seminarios realizodos con estudiantes de Pedagogía en Costellano de la ex-Sede Temuco de la Uhiversidad de Chile y actual Universidad de la Frontera, entre 1979 y 1984.

(27) Sobre la vigencia del mito de Sumpall, puede confrontarse Hugo Carrasco El Mito de Shumpall en relatos orales mapuches, ya citado. Tanbién Adalberto Salas: "Dos cuentos mitológicos mopuches: el sumpall y ot trüike wekufü. Una perspectiva etnográfica en Acta Literaria 8, 1983, pp.5-36. Sobre la vigencia del mito de Morkian", (cfr. los Informes de Avances 1980 y 1982 del Proyecto de Investigación sobre Recopilación y análisis de epeu (relatos orales mapuches), patrocinodo en 1980-81 por el SERVICIO DE DESARROLLO CIENTIFICO de la Universidad de Chile y en 1982-83 por la Dirección de Investigación Científica y Tecnológica de la UFRO.

(28) Claude Lévi-Strauss: Mitológicas 3 El origen de las maneras de mesas. México-Argentina-España, Siglo Veintiuno Editores, 1970 (1968); p.153.

(29) Esta conclusión de Lévi-Strauss ha sido desarrollada analíticamente por R.Foerster, H.González y H.Gundermom en "Kai-Kai y Tren-Tren. Análisis estructural de un grupo de mitos mapuches" en Acta Literaria 3-4. Concepción, Uhiversidad de Concepción; 1978-79; pp.27-40.

(30) Una interesante versión anotada por el P.Housse, mucho más rica, al igual que ésta incluye numerosos elementos autoexegéticos y explicativos. Cfr. en Aída Kurteff: Los 
CULTURA， HOMBRE， SOCIEDAD

(3.1.1986

Araucanos y el misterio de los Andes. B.Aires, Editorial Plus Ultra, 1979; pp.38-40.

(31) En el sentido generalizado por Todorov (1968) a partir de la distinción discurso/historia, fundado en el postulado de Benveniste sobre enunciación/enunciado.

(32) - Según ha propuesto Genette (1972), especialmente en "El discurso del relato", pp.65-224.

(33) Cfr. el Anexo. 
(arrasco)

MANIFESTACIONES LITERARIAS MAPUCHES: ..

A NEXO

\section{EL TRENG TRENG Y EL KAI KAI}

Esto es en tiempos muy remotos, tal vez, żcuántos años será de ésto, no?, que sucedió un caso que pasó a ser cuento. Se trata de que, en un tiempo, hubo una tremenda ovenida, llovió mucho. El tiempo sería muy malo. Y el agua, subía, subía en la noche $y$ de día se estancaba un poquito. Pero había también un cerrito que crecía de día. Entonces, eran dos poderosos; el Treng-treng del cerro y el Kai-kai del agua. En la noche cantaba el del agua: "Kai,kai,kai,kai,kai", subía el agua, y de día el cerrito, cuando se sentía alcanzado decía: "treng,treng,treng", subía el cerrito, y así para poder salvarse la gente en esa época, tuvieron que refugiarse en ese cerro y también toda clase de animales que hay en la naturaleza fueron llegando a ese cerrito, porque perseguidos por el agua, no hallaban dónde ir arrancóndose, entonces, llegaron al cerrito ese. Aquellas personas que tenían miedo de los animales y decían: ley!, tenían que caer al agua. Tenían que morir. Y así fueron salvándose algunos que no tuvieron ese miedo. Pasó mucho tiempo, días tal vez, quizás cuánto tiempo sería que tenían esa lucha esas dos fuerzas: el Treng-treng del cerro y el Kai-kai del agua. "Kai,kai,kai, kai, kai", subía el agua; "treng-treng, treng-treng", decía el cerrito y subía el cerrito. Llegó el momento en que este cerrito y el agua llegaron cerca casi del sol. Según cuentan, la gente entonces, para poder evitar el calor tremendo del sol tuvieron que fabricar un plato, así como de greda, que llaman leute, y se colocaron en la cabeza y así se salvaron del calor. Llegó entonces, el momento en que ya no pudieron ni el cerro subirse más arriba, ni el agua tampoco subir. Y bajó el agua después. Se salvó muy pocas personas y eso fue lo que sucedió en aquellos tiempos. Se salvó muy poca gente $y$ de eso entonces quedó el recuerdo de este cuento de los mapuches.

Entonces, quedó que los mapuches por esa causa, antigua- 
mente, yo supe the visto-, al observar cualquier persona observativa que cada ruca mapuche, en todas partes, aquí especialmente, en esta zona de Cautín, los mapuches siempre eligen un cerrito para hacer su construcción, su casita, su ruquita, porque todos los cerros tienen ese poder de Treng-treng. Si llegase a venir otra vez esa ovenida, tal vez, ellos pensando en eso, el cerrito puede subir. Puede tener esa fuerza del Treng-treng.

Eusebio Painemal, El Coitue, 1979

\section{EL DILUVIO}

Guentan, que hace mucho tiempo atrás, en la tribu Reñico Grande hubo un diluvio. Por entonces existía la culebra del Bien llamada Treng-treng-treng, quien avisó a los mapuches que la culebra del mal Kai-kai, pretendía inundar la tierra y los que querían salvarse de esa inundación tenían que subirse al cerro Treng-treng, donde habitaba la culebra del Bien. Llegó el momento en que las aguas comenzaron a subir tan pronto camo el grito de la culebra Kai-kai. Entre más gritaba esta culebra "kai-kai", más se elevabon las aguas y en ese momento casi se tapó el cerro.

Pero la culebra del Bien acudió para ayudar a los mapuches. La culebra del Bien decía: iTreng-treng! y el cerro subía más que las aguas, pero también las aguas subían, de manera que la competencia ena evidente. Pero hubo un instante en que las aguas no pudieron subir más, porque el cerro subió tanto, que casi se acercó al cielo donde estaba el sol. Y las aguas comenzaron a bajar por el calor que allí reinaba. Las personas que iban en el cerro tuvieron que cubrirse sus cobezas con cántaros quebrados y cestos para protegerse de los fuertes rayos solares. tha vez que las aguas bajaron al nivel acostumbrado, ellos tombién descendieron, y de esa monera pudieron sobrevivir. Sin embargo, hubo algunos que no alcanzaron a sobrevivir, pero la 
culebra del Bien los transformó en peces, cochayuyo, mariscos, y otros elementos del mar, para que se alimentaran los habitantes mapuches.

Juan Carilao Ciriñir, Reñico Grande (Malleco, 1979)

\section{CAI-CAI - TREN-TREN}

Guando hubo el diluvio aquí en el mundo, en esta tierra entonces, ése, dicen, ese cerro "Monte Verde" según cuentan los viejos abuelos míos, que cuando empezó a subir el agua, entonces, el Kai-kai deciía: "Cai,cai,cai, cai,cai, entonces el agua iba subiendo y cuando el Tren Tren sonaba, porque son dos pájaros, según dicen son dos bichos que son parecidos a un monstruo, entonces, ellos se paraban en dos patas camo simulando dos caballos.

Tren Tren deciía: "Tren, tren, tren", y chí calmaba el agua y subía, crecía el cerro, iban creciendo los arbustos y todo el alrededor donde estabon, así que... subían todos los animales que estaban cerca chí y las gentes, grupos de gente, grupos de animales subieron a ese cerro....

Entonces, chí en ese tiempo en que se pelearon esos dos animales... uno era bueno, uno era el que apoyaba al buen espíritu y el otro no. El otro quería liquidar por todo lo que había alrededor de ellos y el otro quería salvarlos: el Tren tren era el que quería salvar a los animales y al ser viviente.

Santos Segundo Quelempón Quidel y Mercedes Neculqueo Llonquitur, Temuco, 1980. 


\section{EL DILUVIO}

En la época del diluvio, el Kai-kai (dios del mal), había enviado mucha agua a los mapuches por no creer en él, lluvia, truenos,. relámpagos, terblores, etc., provocando una inundación en toda la tierra.

Un grupo de mapuches que habían sido avisados, anteriormente, por el Tren-Tren (pájaro avisado enviado por el dios Ngenechén), se fueron al monte más alto con algunos animales y comide para bastante tiempo.

Estuvieron estos mapuches durante muchos meses, todos los dias iba el Tren-tren a decirles cuanto bajaba el agua. Hasta que un día les dijo que podían bajar del monte y que Dios (Ngenechén), estaba muy contento con ellos por creer fielmente en él.

Y con estos pocos mapuches que se habían salvado empezó a nacer de nuevo la población mapuche.

Rosendo Catriñir Ladinö; Puerto Saovedra, 1979. 